https://doi.org/10.15407/ujpe65.4.298

H. HUSHVAKTOV, A. JUMABAEV, G. MURODOV, A. ABSANOV, G. SHARIFOV

Samarkand State University

(15, University Blvd., Samarkand 140104, Uzbekistan; e-mail: jumabaev2@rambler.ru)

\title{
AGGREGATION OF MOLECULES \\ IN LIQUID ETHYLENE GLYCOL AND ITS MANIFESTATION IN EXPERIMENTAL RAMAN SPECTRA AND NON-EMPIRICAL CALCULATIONS ${ }^{1}$
}

\begin{abstract}
Intra- and intermolecular interactions in liquid ethylene glycol have been studied using the Raman spectroscopy method and non-empirical calculations. The results of non-empirical calculations show that an intermolecular hydrogen bond is formed between the hydrogen atom of the $\mathrm{OH}$ group in one ethylene glycol molecule and the oxygen atom in the other molecule. The formation of this bond gives rise to a substantial redistribution of charges between those atoms, which, nevertheless, insignificantly changes the bond length. In the corresponding Raman spectra, the presence of hydrogen bonds between the ethylene glycol molecules manifests itself as the band asymmetry and splitting.
\end{abstract}

Ke ywords: aggregation of molecules, ethylene glycol, spectral manifestation, non-empirical calculations, hydrogen bond, intramolecular interaction, intermolecular interaction, monomer, dimer, aggregate structure.

\section{Introduction}

Among various specific interactions, the hydrogen bond is of particular interest. It is pertinent to plenty of substances in different aggregation states. The development of the hydrogen bond theory was strongly favored by the research of vibrational spectra of compounds with hydrogen bonds, in particular, with the help of Raman spectroscopy. The combination of spectroscopic research methods with quantum chemical calculations of investigated systems allows the nature and characteristic features of the latter to be explained. At present, non-empirical (ab initio) calculations are applied to find correlations between the experiment and the theory, as well as to calculate the properties of molecular structures.

Ethylene glycol is widely used in various branches of industry. Therefore, this substance is intensively studied with the help of various experimental and theoretical methods. Numerous researches testify that an ethylene glycol molecule can exist in ten basic conformations [1]. However, only some of them are stabilized by means of an intramolecular hydrogen bond. The inter- and intramolecular hydrogen bonds in ethylene glycol have been studied to a much less

(C) H. HUSHVAKTOV, A. JUMABAEV, G. MURODOV, A. ABSANOV, G. SHARIFOV, 2020

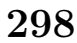

extent, including information obtained in the framework of quantum chemical methods.

In the case of the intramolecular hydrogen bond, different parts of the same molecule become coupled to each other. Compounds with intramolecular hydrogen bonds possess lower melting and boiling points and lower viscosity in the liquid state, because the molecules are weakly connected with one another in this case [1]. The study of intra- and intermolecular interactions using Raman spectra and quantum chemical methods makes it possible to evaluate the possibility of the formation of hydrogen bonds in the cases of both monomers (intramolecular hydrogen bonds) and monomer clusters (intermolecular hydrogen bonds) [2-6].

The aim of this work was to study the aggregation process of ethylene glycol molecules and its spectral manifestation using Raman spectroscopy and quantum chemical model calculations.

\section{Experimental Method} and Non-Empirical Calculation Technique

In our experiment, we used ethylene glycol of the chemically pure grade, which was subjected to the

1 The paper was presented at XXIVth Galyna Puchkovska International School-Seminar "Spectroscopy of Molecules and Crystals" (August 25-30, 2019, Odesa, Ukraine).

ISSN 2071-0194. Ukr. J. Phys. 2020. Vol. 65, No. 4 

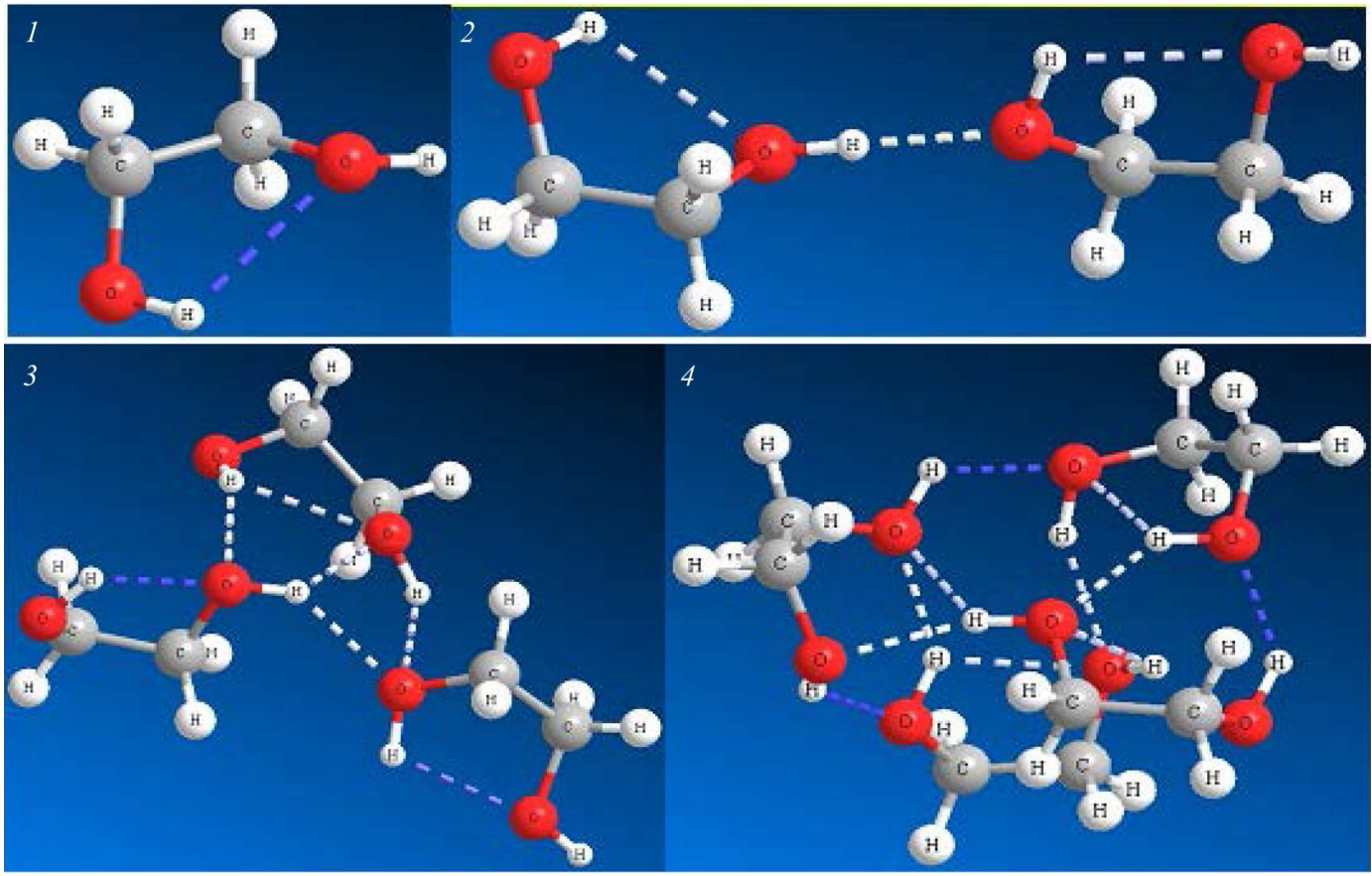

Fig. 1. Calculated structures of ethylene glycol molecules: monomer (1), dimer (2), trimer (3), and tetramer (4). The inter- and intramolecular hydrogen bonds are also shown

additional vacuum distillation. The Raman spectra of ethylene glycol were measured on a Thermo Nicolet 6700 FTIR/FT-Raman spectrometer. All measurements were carried out at room temperature $\left(20{ }^{\circ} \mathrm{C}\right)$.

To compare the results obtained, several approximation methods (RHF, B3LYP, and MP) with a set of Gaussian functions $6-31 \mathrm{G}++(d, p)$ [7] were used, when carrying on non-empirical calculations for the monomer and other isolated high-molecular-weight clusters of ethylene glycol molecules. In all calculations, two $d$ and $p$ orbitals were used.

\section{Results and Their Discussion}

Non-empirical calculations were carried out for the following isolated ethylene glycol molecular aggregates: monomer, dimer, trimer, and tetramer. The structures of those aggregates, as well as all possible intra- and intermolecular interactions between the molecules in them, are shown in Fig. 1.

An ethylene glycol molecule contains two $\mathrm{CH}_{2} \mathrm{OH}$ atomic groups linked to each other by means of a simple bond between their carbon atoms. Therefore, those groups can rotate relative to each other, i.e. various spatial isomers can be formed $[8,9]$. In this regard, although the $\mathrm{CH}_{2} \mathrm{OH}$ groups are iden- tical, the $\mathrm{OH}$ bonds are mutually so arranged that the $\mathrm{CH}_{2} \mathrm{OH}$ monomeric groups should slightly differ from each other in both their atomic charges and the bond lengths between atoms. In any case, the hydrogen atoms of $\mathrm{OH}$ groups can form a hydrogen bond.

The monomer and the dimer of an ethylene glycol molecule were studied in work [10]. Calculations were carried out for a dimer formation, when one of the $\mathrm{OH}$ groups was involved. Of interest is the structure of an aggregate of molecules connected by hydrogen bonds. A fragment in the Raman spectra was studied, which, in our opinion, contained attributes of the hydrogen bond formation. Furthermore, as was shown in work [11], the $\mathrm{CH}_{2} \mathrm{OH}$ groups of ethylene glycol are sometimes different in the bond lengths and, especially, in the atomic charges. Besides two hydrogen bonds, which are formed in the ethylene glycol molecule with the help of an $\mathrm{OH}$ group, the appearance of chain formations and intramolecular hydrogen bonds is also possible.

Our non-empirical calculations showed that intramolecular hydrogen bonds play an important role in the growth of the ethylene glycol boiling point. According to the results obtained, one rather 

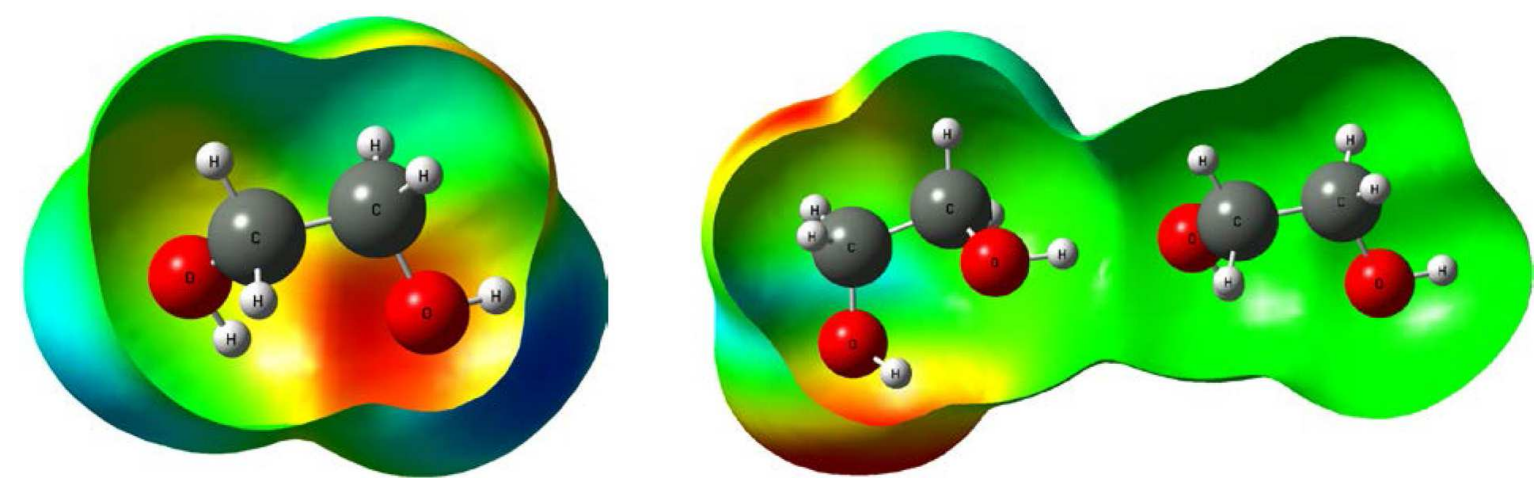

Fig. 2. Charge distributions over the ethylene glycol monomer and dimer

strong intramolecular hydrogen bond is observed for monomeric molecules, and two such bonds are observed for dimers and trimers (Fig. 1, for tetrameric and higher-order aggregates, those intramolecular hydrogen bonds become weaker). This means that the $\mathrm{CH}_{2} \mathrm{OH}$ groups are rotated with respect to each other, which is associated with a potential barrier arising owing to the interaction between the $\mathrm{OH}$ bonds at the ends of the molecule $[11,12]$. In addition, there is also a strong interaction of the hydrogen atoms in the $\mathrm{CH}_{2} \mathrm{OH}$ groups with the oxygen atoms; more specifically, of the hydrogen $\mathrm{H}^{8}$ and $\mathrm{H}^{5}$ atoms with the oxygen $\mathrm{O}^{4}$ and $\mathrm{O}^{2}$ atoms, respectively. The corresponding distances equal $2.061 \AA$ between $\mathrm{H}^{8}$ and $\mathrm{O}^{4}$, and $2.053 \AA$ between $\mathrm{H}^{5}$ and $\mathrm{O}^{2}$, which is close to the average length of an intramolecular H-bond.

Our calculations also showed that an intermolecular hydrogen bond can appear between two ethylene glycol molecules, which results in the formation of a dimeric aggregate [13]. The hydrogen atom from the $\mathrm{OH}$ group of one molecule and one of the oxygen atoms from the other molecule participate in the formation of this bond. According to our calculations, the hydrogen bond energy in the dimer equals $1.26 \mathrm{kcal} / \mathrm{mol}$. In principle, two hydrogen bonds for each $\mathrm{CH}_{2} \mathrm{OH}$ group are possible for ethylene glycol molecules, which allows the formation of molecular chains.

The formation of a dimer gives rise to the redistribution of charges and a change of bond lengths, and those phenomena occur differently for the protondonor and proton-acceptor molecules. Figure 2 illustrates the charge redistribution in a monomer and a dimer of ethylene glycol molecules. The dimer struc- ture makes it possible to judge the charge distribution and the change of bond lengths (Fig. 2).

According to the calculation results, the charge distributions in the molecular aggregates from monomer to tetramer were analyzed. For the calculated structures, the dipole moments of aggregates were found to equal: $2.6 \mathrm{D}$ for the monomer, 6.4 $\mathrm{D}$ for the dimer, 8.4 $\mathrm{D}$ for the trimer, and 2.3 $\mathrm{D}$ for the tetramer. Attention should be paid that the dipole moment decreases with an increase in the number of molecules in the aggregate (see Table). This means that a strong redistribution of bonds occurs in the ethylene glycol aggregates with the growth of the number of hydrogen bonds. For example, the hydrogen bond length equals $1.986 \AA$ for a dimer [10]. The formation of H-bond in a dimer leads to the appearance of three to six new vibrational bands in the spectrum, which are associated with the mutual vibrations of atoms and with the vibrations of the hydrogen bond itself. The indicated bands are located within a spectral interval from 10 to $200 \mathrm{~cm}^{-1}$. The Raman activity in the Raman spectra is low, so that the background wing of the Rayleigh line, the length of which is up to $200 \mathrm{~cm}^{-1}$, does not enable one to be detected.

The registered Raman spectrum of ethylene glycol is shown in Fig. 3. Its study in the interval from 800 to $1500 \mathrm{~cm}^{-1}$ corresponding to $\mathrm{OH}$ vibrations showed that the bands belonging to this interval are rather complicated. In particular, the band at $866 \mathrm{~cm}^{-1}$ is asymmetric on the high-frequency side, two bands near $1060 \mathrm{~cm}^{-1}$ (namely, at 1054 and $1078 \mathrm{~cm}^{-1}$ ) overlap, and the band at $1463 \mathrm{~cm}^{-1}$ looks like a narrow line.

The formation of intermolecular bonds in liquid ethylene glycol manifests itself in the Raman spec-

ISSN 2071-0194. Ukr. J. Phys. 2020. Vol. 65, No. 4 
Results of non-empirical calculations

for ethylene glycol molecules using the B3LYP method

\begin{tabular}{|c|c|c|c|c|c|c|c|c|}
\hline No & $\begin{array}{c}\text { Aggregate } \\
\text { type }\end{array}$ & $\begin{array}{c}\nu_{\mathrm{O}-\mathrm{H}} \\
\mathrm{cm}^{-1}(\mathrm{D})\end{array}$ & $\rho$ & $\begin{array}{c}\nu_{\mathrm{O}-\mathrm{H}} \\
\mathrm{cm}^{-1}(\mathrm{~K})\end{array}$ & $\rho$ & $\begin{array}{c}\Delta E^{*} \\
\mathrm{kcal} / \mathrm{mol}\end{array}$ & $\begin{array}{c}D, \\
\text { debye }\end{array}$ & $\begin{array}{c}\Delta E_{\mathrm{H}}^{* *}, \\
\mathrm{kcal} / \mathrm{mol}\end{array}$ \\
\hline 1 & Monomer & $\begin{array}{l}1169.6 \\
1285.8\end{array}$ & $\begin{array}{l}0.7 \\
0.7\end{array}$ & $\begin{array}{l}3808.3 \\
3857.5\end{array}$ & $\begin{array}{l}0.16 \\
0.24\end{array}$ & 53.6 & 2.6 & \\
\hline 2 & Dimer & $\begin{array}{l}1171.7 \\
1200.5 \\
1287.4 \\
1334.1\end{array}$ & $\begin{array}{l}0.7 \\
0.7 \\
0.6 \\
0.3\end{array}$ & $\begin{array}{l}3658.9 \\
3793.1 \\
3796.2 \\
3857.3\end{array}$ & $\begin{array}{l}0.3 \\
0.12 \\
0.13 \\
0.25\end{array}$ & 108.2 & 6.4 & 1.26 \\
\hline 3 & Trimer & $\begin{array}{c}1074.0 \\
1171.8 \\
1274.2 \\
1287.9 \\
13.28 .9 \\
1360.8\end{array}$ & $\begin{array}{l}0.45 \\
0.75 \\
0.62 \\
0.70 \\
0.37 \\
0.72\end{array}$ & $\begin{array}{l}3521.5 \\
3615.2 \\
3654.3 \\
3793.2 \\
3798.6 \\
3857.3\end{array}$ & $\begin{array}{l}0.18 \\
0.39 \\
0.22 \\
0.11 \\
0.13 \\
0.25\end{array}$ & 163.3 & 8.4 & 2.87 \\
\hline 4 & Tetramer & $\begin{array}{c}1205.4 \\
1296.5 \\
1369.9 \\
13.96 .6 \\
1423.9 \\
1437.3 \\
1445.7 \\
1447.0\end{array}$ & $\begin{array}{l}0.74 \\
0.75 \\
0.52 \\
0.37 \\
0.55 \\
0.63 \\
0.70 \\
0.67\end{array}$ & $\begin{array}{l}3175.5 \\
3244.7 \\
3307.0 \\
3380.1 \\
3478.0 \\
3515.6 \\
3614.1 \\
3617.5\end{array}$ & $\begin{array}{l}0.02 \\
0.59 \\
0.57 \\
0.34 \\
0.21 \\
0.21 \\
0.05 \\
0.73\end{array}$ & 214.9 & 2.8 & 1.08 \\
\hline
\end{tabular}

* The vibrational energy of an isolated molecule (the quantum mechanical system) at the zero point.

** The energy of intermolecular hydrogen bond.

tra as the asymmetry of the bands at 866,1054 , and $1078 \mathrm{~cm}^{-1}$. The half-width of the combined band consisting of two lines at 1054 and $1078 \mathrm{~cm}^{-1}$ amounts to $57 \mathrm{~cm}^{-1}$. These bands belong to planar deformation vibrations of the $\mathrm{O}-\mathrm{H}$ bond. According to our calculations, the asymmetry observed in the Raman spectra stems from the appearance of aggregate vibrations at frequencies located on the high-frequency side of the monomer band.

The calculated values of the band frequencies are as follows: for the $866-\mathrm{cm}^{-1}$ band, the calculations give dimer bands at 950.9 and $954.2 \mathrm{~cm}^{-1}$, with a frequency difference between them of about $4 \mathrm{~cm}^{-1}$. Perhaps, the asymmetry of the $866-\mathrm{cm} \mathrm{cm}^{-1}$ is associated with this complexity. A doublet structure is also obtained for the band at 1054$1078 \mathrm{~cm}^{-1}$; namely, the calculated values are 1159.2 and $1171.8 \mathrm{~cm}^{-1}$, with a frequency difference of about $21 \mathrm{~cm}^{-1}$ against an experimental value of about $24 \mathrm{~cm}^{-1}$ (Fig. 4).

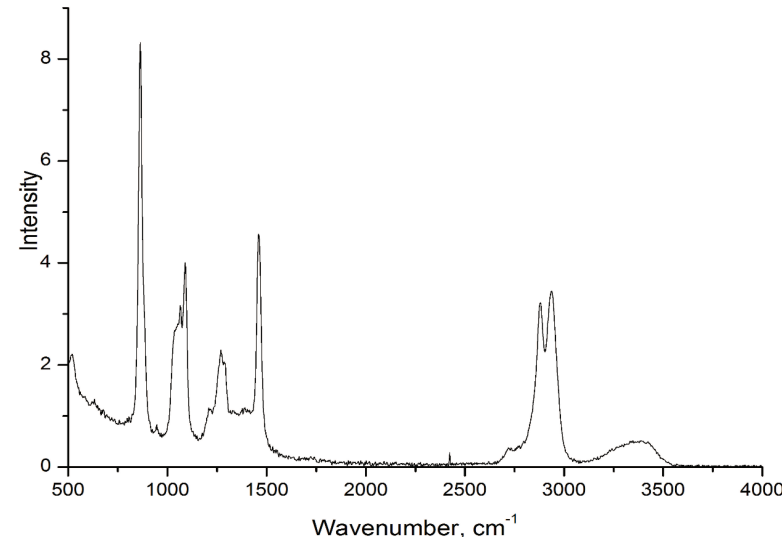

Fig. 3. Raman spectrum of ethylene glycol

Note that the calculated frequencies differ from the experimental ones by about $10 \%$. A coincidence of the values for the ethylene glycol monomer and dimer can be achieved with the help of a correlation factor [14]. 

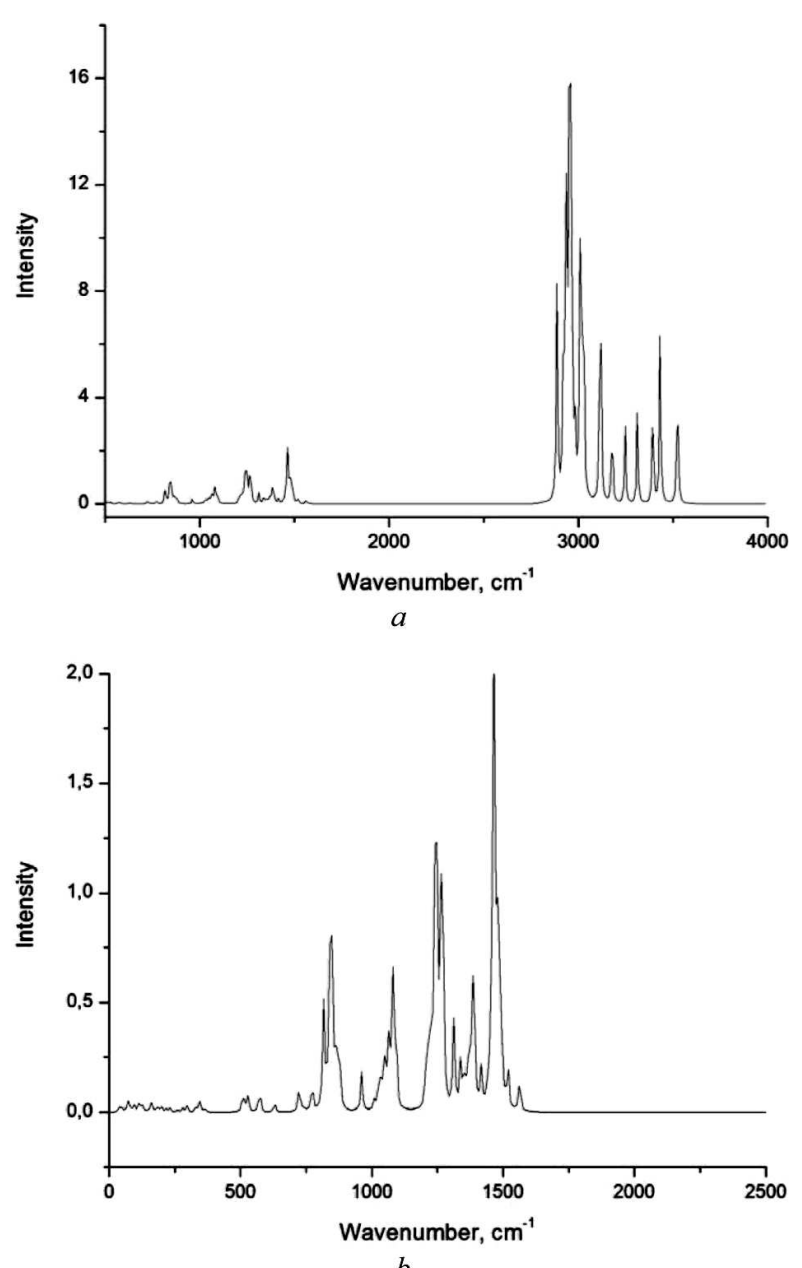

Fig. 4. Theoretical Raman spectra of ethylene glycol: $(a)$ the whole spectrum, (b) the bands in an interval of $800-1500 \mathrm{~cm}^{-1}$

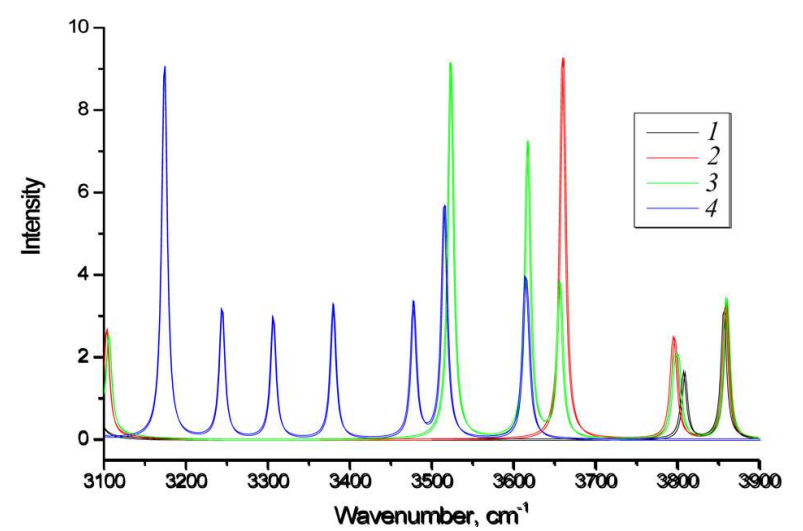

Fig. 5. Raman spectra of ethylene glycol calculated using the B3LYP method: monomer (1), dimer (2), trimer (3), and tetramer (4)
In Fig. 5, the calculated Raman spectra of $\mathrm{OH}$ vibrations in ethylene glycol for the monomer, dimer, trimer, and tetramer aggregates are depicted. One can see that, when the number of molecules (the number of hydrogen bonds) increases, the band shifts toward low frequencies (the corresponding shift achieves a value of $\left.632.8 \mathrm{~cm}^{-1}\right)$. This behavior is in good agreement with the results of work [15].

The analysis of the experimental Raman spectra and the calculations show that ethylene glycol molecules form dimers with the antiparallel orientations of their molecules by means of the hydrogen bond. As the number of molecules in the aggregate increases, the appearance of inter- and intramolecular hydrogen bonds in liquid ethylene glycol manifests itself more distinctly in the Raman spectra. The formation of the H-bond in a dimer leads to the emergence of three to six new vibrational bands in the vibrational spectrum. Those bands are associated with mutual vibrations of molecules and their vibrations around the hydrogen bond.

1. M.A. Krestyaninov, A.G. Titova, A.M. Zaichikov. Intraand intermolecular hydrogen bonds in ethylene glycol, monoethanolamine, and ethylenediamine. Zh. Fiz. Khim. 88, 1939 (2014) (in Russian).

2. I.Yu. Doroshenko, V.E. Pogorelov, G.A. Pitsevich, V. Shablinskas. Cluster Structure of Liquid Alcohols: Vibrational Spectroscopy Study (LAMBERT Acad. Publ., 2012) (in Russian).

3. V. Pogorelov, L. Bulavin, I. Doroshenko, O. Fesjun, O. Veretennikov. The structure of liquid alcohols and the temperature dependence of vibrational bandwidth. J. Mol. Struct. 708, 61 (2004).

4. G.A. Pitsevich, I.Yu. Doroshenko, V.Ye. Pogorelov, E.N. Kozlovskaya, T. Borzda, V. Sablinskas, V. Balevicius. Long-wave Raman spectra of some normal alcohols. Vibr. Spectrosc. 72, 26 (2014).

5. P. Golub, I. Doroshenko, V. Pogorelov. Quantum-chemical modeling of energy parameters and vibrational spectra of chain and cyclic clusters of monohydric alcohols. Phys. Lett. A 378, 1937 (2014).

6. A. Vasylieva, I. Doroshenko, Ye. Vaskivskyi, Ye. Chernolevska, V. Pogorelov. FTIR study of condensed water structure. J. Mol. Struct. 1167, 232 (2018).

7. M.J. Frisch, G.W. Trucks, H.B. Schlegel, G.E. Scuseria, M.A. Robb, J.R. Cheeseman, G. Scalmani, V. Barone, B. Mennucci, G.A. Petersson, H. Nakatsuji, M. Caricato, X. Li, H.P. Hratchian, A.F. Izmaylov et al. Gaussian 03, Revision A.02 (Gaussian, 2003).

8. V.M. Bilobrov. Hydrogen Bond: Intramolecular Interactions (Naukova Dumka, 1991) (in Russian).

ISSN 2071-0194. Ukr. J. Phys. 2020. Vol. 65, No. 4 
9. Ye. Vaskivskyi, Ye. Chernolevska, A. Vasylieva, V. Pogorelov, R. Platakyte, J. Stocka, I. Doroshenko. 1-hexanol conformers in a nitrogen matrix: FTIR study and high-level ab initio calculations. J. Mol. Liq. 278, 356 (2019).

10. F.H. Tukhvatullin, U.N. Tashkenbaev, A. Jumabaev, H.A. Hushvaktov, A.A. Absanov, B. Hudoyberdiev. Manifestation of the intermolecular interactions in Raman spectra and ab initio calculations of molecular aggregation in liquid ethylene glycol. Ukr. J. Phys. 59, 219 (2014).

11. A. Kaiser, M. Ritter, R. Nazmutdinov, M. Probst. Hydrogen bonding and dielectric spectra of ethylene glycol-water mixtures from molecular dynamics simulations. J. Phys. Chem. B 120, 10515 (2016).

12. P. Kumar, S.R. Varanasi, S. Yashonath. Relation between the diffusivity, viscosity, and ionic radius of $\mathrm{LiCl}$ in water, methanol, and ethylene glycol: A molecular dynamics simulation. J. Phys. Chem. B 117, 8196 (2013).

13. R.-Sh. Luo, J. Jonas. Raman scattering study of liquid ethylene glycol confined to nanoporous silica glasses. J. Raman Spectrosc. 32, 975 (2001).

14. P. Pulay, G. Fogarasi, G. Pongar, I.E. Boggs, A.Varga. Combination of theoretical ab initio and experimental information to obtain reliable harmonic force constants. Scaled quantum mechanical (SQM) force fields for glyoxal, acrolein, butadiene, formaldehyde, and ethylene, J. Am. Chem. Soc. 105, 7037 (1983).

15. F.H. Tukhvatullin, V.Ye. Pogorelov, A. Jumabaev, H.A. Hushvaktov, A.A. Absanov, A. Usarov. Polarized components of Raman spectra of $\mathrm{O}-\mathrm{H}$ vibrations in liquid water. J. Mol. Liq. 160, 88 (2011).

Received 03.11.19.

Translated from Russian by O.I. Voitenko

Х. Хушвактов, А. Жумабаєв,

Г. Муродов, А. Абсанов, Г. Шарифов

АГРЕГАЦІЯ МОЛЕКУЛ У РІДИННОМУ

ЕТИЛЕНГЛІКОЛІ, ЙОГО ПРОЯВ У СПЕКТРАХ

КОМБІНАЦІЙНОГО РОЗСІЮВАННЯ

I НЕЕМПІРИЧНІ РОЗРАХУНКИ

$\mathrm{P}$ е $з$ ю м е

Досліджено внутрішньо- і міжмолекулярну взаємодію в етиленгліколі методом комбінаційного розсіювання світла і неемпіричних розрахунків. Неемпіричними розрахунками показано, що між атомом водню ОН групи однієї молекули і атомом кисню іншої молекули утворюється міжмолекулярний водневий зв'язок, що приводить до істотного перерозподілу зарядів між атомами і незначних змін довжин зв'язків. В спектрах комбінаційного розсіювання наявність водневого зв'язку між молекулами проявляється у вигляді асиметрії і розщеплення смуг. 